\title{
Development Situation and Future Prospects of Cultural and Creative Industry in Third-tier Cities in China
}

\author{
Xinquan Wang \\ Arts and Media College of Bohai University, Jinzhou Liaoning, 121000, China
}

Keywords: third-tier city; cultural and creative industry; development situation; future prospect

\begin{abstract}
In recent years, domestic cultural and creative industry develops rapidly, however, there is large difference in its development speed and quality between third-tier cities and first-tier and second-tier cities. This paper discusses the development situation, puts forward suggestions, and makes future prospects for cultural and creative industry in third-tier cities in China.

As an emerging industry with unique industry attribute, cultural and creative industry plays an important role in promoting economic development, and satisfying the requirements of humanistic spirits. As a new growth point of national economy, the economic value of cultural and creative industry accounts for 3.77\% of GDP in 2014, having completed the transformation from emerging industry to pillar industry of national economy to some extent.
\end{abstract}

\section{The Development Situation of Cultural and Creative Industry in Third-tier Cities}

At present, the development of cultural and creative industry in domestic third-tier cities increases continuously, however, there are many problems, and this paper analyzes its development situation.

\subsection{The low overall quality of the development of cultural and creative industry}

Cultural and creative industry in most third-tier cities in China is still in initial stage with relatively small scale of industrial park, mainly including software, network and computer services. The construction of industrial park is not excellent with few cultural and creative enterprises and most industrial parks are still in construction or in investment promotion. Cultural and creative industry develops rapidly in the speed, whereas, low in the quality. Industrial planning is relatively unclear, lacking operability, and industrial category is in disorder with seriously unbalanced development.

\subsection{The lack of advantageous industrial cluster in cultural and creative industry}

The development of cultural and creative industry is driven by leading enterprises. For most domestic third-tier cities, there is no famous brand or leading industry that can rapidly promote the sustainable development of cultural and creative industry to become the cultural and creative industrial cluster with a certain scale. Therefore, there is a long way to go for third-tier cities in cultural and creative industrial cluster.

\subsection{The lack of management in cultural and creative industry}

The upgrading pattern of cultural and creative industry is the formation of industrial cluster, and in this way, win-win can be realized to the utmost extent. However, based on current situation, there are many problems in industrial parks in most third-tier cities. First of all, the constraint for enterprises entering industrial park is strict, the plan of enterprise category in industrial park is incomplete, the distribution of enterprises in industrial park is dispersive and there is no strict standard for some enterprises. Secondly, the cooperation between enterprises in industrial park is relatively insufficient. In general, enterprises in industrial park just cooperate with upstream firms in Guangzhou, Shenzhen or other by cities. In other words, they just form the cluster in space, whereas, the awareness of cooperation is weak and development space is small. Finally, there exist 
some problems in the communication between the management committee of industrial park and enterprises, and it is difficult for enterprises to effectively solve problems and provide help. At the same time, it can be found that there is not platform of information exchanges in industrial park and enterprises cannot obtain information rapidly.

\subsection{The imperfect intellectual property protection system and public service platform}

The impeding factor of sustainable development of Chinese cultural and creative industry is the lack of perfect intellectual property protection system and public service platform. The cultural and creative industry and public service platform is backward to some extent. According to statistics of cultural and creative industry, many cultural and creative enterprises start from a low base and remain in initial stage, lacking hardware and software equipment, related talents, and the capability to research product, and requiring comprehensive services form government and industrial park.

The innovation of cultural and creative products requires high cost and heavy investment, however, the technology and production cost of cultural and creative product imitation and copying is low. Thus, government shall pay attention to intellectual property protection and formulate sound laws and regulations, which has an important influence on stable and sustainable development of cultural and creative industry. The government in some regions have not issued laws and regulations system of intellectual property protection specific to cultural and creative industry and effective enforcement supervision system.

\subsection{The lack of high-level innovative talents in cultural and creative industry}

The development of cultural and creative industry is traditional knowledge-intensive and technology-intensive industry, and an industry with highly integrated knowledge, culture and technology, mainly relying individual creativity, skills and competence. The greatest obstacle in the development of cultural and creative industry in third-tier cities is the lack of reserve of creative talents, which is indispensable in each aspect of cultural and creative industry and closely related to the quality and development level of cultural and creative industry. Whereas, cultural and creative industry in most third-tier cities in China is constrained by talents.

As an emerging industry, cultural and creative industry mainly focuses on the creativity and development of knowledge and technology, and the core is high-quality talents. Many leaders of cultural and creative enterprises believe that the lack of talents in design and management greatly limits the healthy development of cultural and creative industry with backward brand construction and weak brand competitiveness. For most third-tier cities, it is necessary to change brand competitiveness. However, the current brand construction in third-tier cities is backward, and the brand consciousness is weak, which leads to the low development of brand and the lack of specific brand positioning in most enterprises. Besides, some enterprises have not built specific department or position of brand management. Most enterprises pay attention to development strategy of enterprise brand, however, because of the small scale, the initial development, or other restraining factors of enterprise, there is specific brand design and promotion strategy in enterprises.

\section{Suggestions on the Development of Cultural and Creative Industry in Third-tier Cities}

\subsection{To strengthen the guidance of government and integrate resources}

It is necessary to strengthen the key role of government, coordinately develop cultural and creative industry, optimize urban resource allocation and formulate a series of policies to promote the prosperous development of cultural and creative industry. First of all, government shall pay more attention to the development of cultural and creative industry, intensify the construction of regional cultural and creative industry and continuously improve the development strategies for cultural and creative industry to realize benign development. Secondly, relevant supervision committee shall be established to effectively supervise the rights of management personnel of industrial park to avoid power abuse, and ensure the implementation of supporting policy from government, and the fair and impartial environment, and the construction of professional public 
platforms for government information disclosure.

\subsection{To widen financing channel of cultural and creative industry}

More than $90 \%$ of cultural and creative enterprises in China is small, medium and micro-sized enterprises, whose main obstacle is the difficult financing, also the lack of capital. Therefore, local government shall take a series of effective measures to solve the problem and offer financing platforms and supporting measures as many as possible. Specifically, government shall provide certain support fund for enterprises with good market development prospects and products with strong market competitiveness; build relevant development fund, decrease interest rate for small and medium-sized cultural and creative enterprises, or consider to offer certain interest subsidies, and reduce or exempt tax; provide certain entrepreneurial space, reduce rent and property management fee; actively build some crowfunding platforms, and learn from practices of developed countries in financing of cultural and creative industry.

\subsection{To improve intellectual property protection system}

The development of cultural and creative industry in China is unbalanced and lacks intellectual property protection. Therefore, relevant departments shall, first of all, perfect law system of intellectual property protection to effectively protect the rights and interests of owners; secondly, it is necessary to perfect enforcement supervision system of intellectual property protection to strive to realize clear division of labor and powerful law enforcement system. Thirdly, the construction of public service system of intellectual property protection shall be intensified, and related institution construction shall be strengthened and relevant programs shall be widen and improved to strengthen intellectual property protection. Finally, government should strengthen the universal education of cultural and creative industry, and enhance self-protection awareness to promote enterprises to fully recognize the importance of infringement and avoid the infringement of intellectual property.

\subsection{To promote the establishment of cultural and creative industrial park}

To fasten industrial cluster. The establishment of cultural and creative industrial park is the experience of Chinese government learnt from industrial development, which can realize resource integration, expand the scale, and can greatly improve the production capability and comprehensive strength of cultural and creative industry. The development of cultural and creative industrial park is beneficial to advance the cooperation and coordination between different enterprises, and for government to intensify the construction of relevant infrastructure to lay a foundation for the development of cultural and creative industry. The series of cultural and creative products published by Disney or Boonie Bears are helpful to give full play to the value of creativity and the maximization of benefits.

\subsection{To cultivate and introduce excellent talents}

The main obstacle in the development of cultural and creative industry is the lack of innovative talents, so it is important to cultivate and introduce more talents. At present, the current talents in cultural and creative industry cannot satisfy the requirements of the industry, thus, Chinese cultural and creative enterprises lack the vitality and the development is far lower than Japan, Europe and the U.S. Therefore, it is urgent to cultivate and introduce cultural and creative talents for the development of cultural and creative industry in third-tier cities in China.

\section{Future Prospects of Cultural and Creative Industry in Third-tier Cities}

The cultivation of innovative talents, first of all, requires local colleges and universities to construct or reconstruct relevant majors, strengthen the cultivation of applied talents, improve related cultivation system and conduct training activities of talents in all levels; secondly, it is necessary to introduce talents, formulate relevant system and attract more innovative talents in local enterprises. Without high-quality creative talents, the development of high-quality and high-standard of local cultural and creative industry is empty talk. This paper analyzed the status 
quo of cultural and creative industry and puts forward suggestions and prospects of rapid development so as to promote the continuous and stable development of cultural and creative industry and provide guarantee for the discipline development of cultural geography.

(1) Cultural and creative industry shall mainly rely on cultural industry, with the core of innovative planning, make use of great development potential of emerging cultural industry based on the development of new media technology, including design, software, network and computer service, to promote the upgrading of urban industrial structure and realize new power of transformation.

(2) In order to promote the stable development of cultural and creative industry in third-tier cities, it is necessary to strengthen the cultivation of talents, formulate preferential policy in investment and financing, land and finance and tax, incessantly intensify cluster development and the establishment of industrial cluster to actively participate in international competence and improve international level.

\section{References}

[1] Zhou Zhiping. The Status of Cultural and Creative Industries in China and Countermeasure [J]. Reformation\& Strategy, 2011. 10.

[2] Wang Tianzheng. Problems and Countermeasures of Cultural and Creative Industrial Parks in China [J]. Contemporary Communications, 2011.4.

[3] Liu Yang. The Development of Cultural and Creative Industry in China [J]. Problem Research, 2013. (2).

[4] Wang Liulin. The Development and Problems of Cultural and Creative Industries [J].2013 (1) 12-15.

[5] Ma Renfeng, Tang Jiao, Zhang Tao et al. Research Dynamics and Chinese Issues of the Development of Cultural and Creative Industry Driven by Scientific and Technological Innovation [J]. Inquiry into Economic Issues, 2012(11): 93-99.

[6] Zhou Qiansong. On the Rapid Development of Cultural and Creative Industry in the Period of $12^{\text {th }}$ Five-Year $[\mathrm{J}]$. Journal of Henan Institute of Science and Technology (Social Sciences Edition), 2011(5): 21-25.

[7] Zeng Jin. Research on Cultural Creative Industry Cluster Development Countermeasure [J]. Science \&Technology Progress and Policy, 2000(15):71-76. 